\title{
Trophic cascade driven by behavioural fine-tuning as naïve prey rapidly adjust to a novel predator
}

\author{
Chris Jolly ${ }^{1}$, Adam Smart ${ }^{2}$, John Moreen ${ }^{3}$, Jonathan Webb ${ }^{4}$, Graeme Gillespie ${ }^{5}$, and Ben \\ Phillips ${ }^{6,6}$ \\ ${ }^{1}$ University of Melbourne School of BioSciences \\ ${ }^{2}$ The University of Melbourne \\ ${ }^{3}$ Kenbi Rangers \\ ${ }^{4}$ University of Technology Sydney \\ ${ }^{5}$ Northern Territory Government of Australia \\ ${ }^{6}$ University of Melbourne
}

August 11, 2020

\begin{abstract}
The arrival of novel predators can trigger trophic cascades driven by shifts in prey numbers. Predators also elicit behavioural change in prey populations, and this may also contribute to trophic cascades. We document rapid demographic and behavioural changes in rodent populations (grassland melomys) following the introduction of an ecologically novel predator (northern quoll). Within months, melomys from quoll-invaded populations suffered reduced survival relative to quoll-free populations. They also exhibited increased shyness which became fine-tuned to more threat-specific antipredator behaviour. These behavioural shifts were associated with lower per-capita seed take, and avoidance of quoll-scented seeds. These behavioural shifts could reflect phenotypic plasticity or may be adaptive responses to selection imposed by predation. Overall, our study reveals rapid numerical and behavioural shifts in response to a novel predator and shows that both behavioural and numerical responses can drive trophic cascades.
\end{abstract}

Trophic cascade driven by behavioural fine-tuning as naïve prey rapidly adjust to a novel predator

CHRIS J. JOLLY*1, ADAM S. SMART ${ }^{1}$, JOHN MOREEN ${ }^{2}$, JONATHAN K. WEBB ${ }^{3}$, GRAEME R. GILLESPIE $^{1,4}$ AND BEN L. PHILLIPS ${ }^{1}$

${ }^{1}$ School of BioSciences, University of Melbourne, Parkville Vic 3010 Australia

${ }^{2}$ Kenbi Rangers, Mandorah NT 0822 Australia

${ }^{3}$ School of Life Sciences, University of Technology Sydney, Broadway NSW 2007 Australia

${ }^{4}$ Flora and Fauna Division, Department of Environment and Natural Resources, Northern Territory Government, Berrimah NT 0828 Australia

\section{Correspondence}

C. J. Jolly

Email: cjolly1@student.unimelb.edu.au

Phone: +61 418259161 
A. S. Smart: adam.steven.smart@gmail.com; J. Moreen: Kenbi@nlc.org.au; J. K. Webb: Jonathan.Webb@uts.edu.au; G. R. Gillespie: Graeme.Gillespie@nt.gov.au

Running title: Behavioural adjustments to a novel predator

Keywords Antipredator behaviour, boldness, invasion, neophobia, novel predator, predator-prey dynamics, prey naivety

This article has been peer-reviewed and recommended by Prof. Denis Réale at Peer Community in Ecology https://ecology.peercommunityin.org/public/rec?id=82

Preprint DOI : https://doi.org/10.1101/856997

Submitted for consideration as a Letter in Ecology Letters

WORDS Abstract: 138; Main text: 4974

REFERENCES 63

FIGURES 5

\section{AUTHORSHIP}

CJJ and BLP designed the study; CJJ, ASS, JM and BLP collected data; CJJ and BLP performed analyses and wrote the manuscript; all authors (except JM) contributed to revisions.

\section{DATA AVAILABILITY STATEMENT}

The datasets and code generated during this study are available via zenodo.org and can be accessed via https://zenodo.org/record/3936466\#.Xy9fChMzZTY

\section{SUPPORTING INFORMATION}

Additional supporting information may be found online in Supporting Information sections at the end if the article.

The arrival of novel predators can trigger trophic cascades driven by shifts in prey numbers. Predators also elicit behavioural change in prey populations, and this may also contribute to trophic cascades. We document rapid demographic and behavioural changes in rodent populations (grassland melomys) following the introduction of an ecologically novel predator (northern quoll). Within months, melomys from quoll-invaded populations suffered reduced survival relative to quoll-free populations. They also exhibited increased shyness which became fine-tuned to more threat-specific antipredator behaviour. These behavioural shifts were associated with lower per-capita seed take, and avoidance of quoll-scented seeds. These behavioural shifts could reflect phenotypic plasticity or may be adaptive responses to selection imposed by predation. Overall, our study reveals rapid numerical and behavioural shifts in response to a novel predator and shows that both behavioural and numerical responses can drive trophic cascades.

\section{INTRODUCTION}

Predation is one of the most pervasive and powerful forces acting on populations. Not only does predation directly impact a population's demography (Schoener \& Spiller 1996), it also imposes natural selection (Abrams 2000). The pressure that predators impose on populations will vary through time and space for many reasons, including tightly coupled predator-prey dynamics, predator movement, prey switching, or stochastic processes (Lima \& Dill 1990; Sih 1992). The fact that predation is not constant, and that antipredator defences may be costly, suggests that flexible responses to predation pressure will often be favoured (Sihet al. 2000; Berger et al. 2001). There is, in fact, a great deal of empirical evidence that flexible responses to predation are common and vary with the perceived risk of predation (e.g. Relyea 2003; Brown et al. 2013; Cunningham et al. 2019). 
Predators also play a powerful role in structuring communities (Esteset al. 2011). Some of our best evidence for this comes from the introduction of novel predators. Invasive predators can cause extinctions (Medina et al. 2011; Woinarski et al. 2015; Doherty et al. 2016), and alter trophic structures and ecosystem function within recipient communities (Courchamp et al. 2003; Simberloff et al. 2013). These cascading outcomes are often treated as purely numeric effects: predators depress the size of prey populations, and the altered numbers of prey can cause cascading numerical changes down trophic levels (Ripple et al. 2001). These numerical effects are undeniably important, but the fact that predators can also elicit phenotypic change in prey populations - through phenotypic plasticity and natural selection-means that subtler ecological effects may also manifest. Prey species living alongside predators may forage at different times, or in different places compared with the same species in a predator-free environment (Laundre et al. 2010). Such behavioural shifts can alter downstream species interactions in potentially complex ways (Fortin et al. 2005; Suraci et al. 2016).

Because predator invasions are rarely intentional or anticipated, there is a scarcity of controlled empirical work on the effects of novel predators on recipient communities and the mechanisms via which these effects play out (but see Lapiedra et al. 2018; Pringle et al. 2019). Such tests are needed, however, if we are to predict invasive species impacts, and improve both conservation management (Sihet al. 2010a) and our understanding of how communities are structured (Sax et al. 2007).

Northern quolls (Dasyurus hallucatus ) were, until recently, a common predator across northern Australia. They have declined over the last several decades, following the general decline in northern Australian mammals (Woinarski et al. 2015)(Braithwaite \& Griffiths 1994). More recently, the invasion of toxic invasive prey (cane toads, Rhinella marina) has resulted in dramatic, range-wide population declines in northern quolls (Shine 2010; Oakwoodet al. 2016)(Moore et al. 2019). For their conservation, northern quolls have recently been introduced to a number of offshore islands where they have never previously existed.

In 2017, a population of 54 northern quolls were introduced to a $25 \mathrm{~km}^{2}$ island off the coast of northwestern Northern Territory, Australia (Kelly 2019). Prior to this introduction, Indian Island (Kabarl) lacked mammalian predators, and large native reptilian predators had recently been reduced to near extinction by the invasion of cane toads. We take advantage of the introduction of northern quolls to a new island to directly test the effects of quolls as a novel predator on an island ecosystem and observe how native prey populations adjust to mitigate the impacts of their arrival. Since quolls are an ecologically novel predator on this island, we predict that this introduction may result in demographic effects (reduced survival and abundance) in invaded prey populations. If behavioural adjustments are able to reduce the demographic effects of a novel predator, we predict rapid behavioural changes in quoll-exposed melomys populations, such as changes in personality composition, foraging behaviour and responses to predator-scent, may manifest through time.

\section{METHODS}

\section{Introduction of northern quolls}

In May 2017, 54 adult northern quolls were introduced to the north-eastern tip of Indian Island, Bynoe Harbor, Northern Territory, Australia (12³7'24.60"S, $130^{\circ} 30^{\prime} 0.72$ "E) to field test the conservation strategy of targeted gene flow (Kelly \& Phillips 2016). Quolls are a voracious, opportunistic generalist predator $(<$ 1.5k g; Oakwood 1997), and their introduction presented an opportunity to monitor the behavioural and demographic impacts on grassland melomys (Melomys burtoni), a native mammalian granivorous prey species (mean body mass $56 \mathrm{~g}, 5.6-103.7 \mathrm{~g}$ ). Logistical challenges prevented us from implementing a BeforeAfter Impact-Control study design (see Supporting Information). Here, we present data from before the introduction of quolls from one invaded site only. Most of our data compare quoll-invaded (impact) versus quoll-free (control) sites over time, commencing within a few months of quoll arrival.

\section{Melomys population monitoring}

To determine whether the arrival of a novel predator resulted in demographic impacts (population size and survival) to a native prey species, we monitored four "impact", quoll-invaded sites established in the north 
of Indian island in the vicinity of where quolls were released and three "control", quoll-free sites established in the south of the island (Fig. 1). Populations of melomys on Indian Island were monitored during four trips occurring immediately prior to the introduction of quolls in May (site 1) 2017, and after the introduction of quolls August 2017 (sites 2-7), April 2018 (sites 1-7), and May 2019 (sites 1-7).

\section{Hosted file}

image1.emf available at https://authorea.com/users/349935/articles/474906-trophic-cascadedriven-by-behavioural-fine-tuning-as-na\%C3\%AFve-prey-rapidly-adjust-to-a-novel-predator

Figure 1. Map showing the arrangement of grassland melomys (Melomys burtoni) monitoring sites on Indian Island, Northern Territory, Australia. Quolls were present at the four monitoring sites in the north of the island and quolls were absent from the three monitoring sites in the south of the island for the duration of the study.

Melomys were monitored at seven independent 1 ha $(100 \mathrm{~m} \times 100 \mathrm{~m}$ ) plots (sites 1-7) spread out across Indian Island using a standard mark-recapture trapping regime designed for a monitoring project (Begget al. 1983; Kemper et al. 1987). Sites in the north (quoll-invaded) and south (quoll-free) of the island were between 8.7 and $9.8 \mathrm{~km}$ apart (Fig. 1; Table S1) and were composed of similar habitat types. The northern and southern sections of Indian Island are divided by mangrove habitat which is inundated at high tide. Cage and camera trapping as well as track surveys confirmed that quolls were present at the "impact" sites and absent from the "control" sites for the duration of the study (Jolly et al. unpub. data).

Each of the seven monitoring sites consisted of 100 Elliott traps (Elliott Scientific Equipment, Upwey, Victoria) spaced at $10 \mathrm{~m}$ intervals in a $10 \times 10$ grid. Most trapping grids were open for four nights, however, the first trapping grid (site 1, May 2017) was open for six nights. After four trap nights, the majority of the melomys population had been captured at least once (Jolly et al. 2019). Traps were baited with balls of peanut butter, rolled oats and honey. These baits were replaced daily for the duration of each trapping session. Traps were checked for captures early each morning and all traps were cleared within two hours of sunrise.

Captured melomys were weighed $(\mathrm{g})$ and sexed. Before release, each melomys was implanted with a microchip (Trovan Unique ID100). On successive mornings, all melomys were scanned (Trovan LID575 Handheld Reader), and any new individuals were microchipped. On the last morning of each trapping session, all melomys caught were retained for behavioural assays. Throughout the study 439 individual melomys were captured and given microchips (melomys caught per site: site $1=83$; site $2=52$; site $3=63$; site $4=59$; site $5=69$; site $6=59$; and site $7=54)$. Of these, $146(33 \%)$ were caught on the final night of trapping and were retained for behavioural trials. Only large, healthy juveniles $(n=11)$, adult males $(n=58)$, and adult non-visibly pregnant females $(n=77)$ were retained for behavioural experiments. Melomys were retained in their respective Elliott traps and taken to the field station for diurnal husbandry. They were provided food and water ad libitum until 2 hours prior to testing. At this point, in an attempt to standardise hunger levels, access to food and water was removed. Indian Island is remote and uninhabited by humans, so all behavioural experiments were conducted in the field under near natural conditions (see Jolly et al. 2019 for detailed experimental procedures).

\section{Modified open field tests}

We employed modified open field tests (also referred to as emergence tests: see Brown \& Braithwaite 2004; López et al. 2005; Carteret al. 2013; Jolly et al. 2019) to assess boldness in grassland melomys and whether the arrival of a novel predator resulted in behavioural shifts in invaded populations. All open field tests were conducted on the night after the last trap night (night 5) and in opaque-walled experimental arenas $(540 \mathrm{~mm} \times 340 \mathrm{~mm} \times 370 \mathrm{~mm})$. Experimental arenas were modified plastic boxes that had an inverted Elliott trap sized hole cut in one end and were illuminated by strings of red LED lights (Jolly et al. 2019). Each experimental arena had natural sand as substrate, and a rolled ball of universal bait (peanut butter, oats and honey) located both in the centre and along one wall of the arena (Jolly et al. 2019). After dark, Elliott traps 
containing a melomys were inserted into the hole in the side of each experimental arena and melomys were allowed to habituate for $10 \mathrm{~min}$. At the start of each trial, Elliott trap doors were locked open - the inverted orientation of the trap prevented them from being triggered closed. Melomys were given 10 min to explore the open field arena. After $10 \mathrm{~min}$, individuals were rounded back into their retreat (the Elliott trap) and a novel object (standard red, plastic disposable bowl) was placed at the end of the arena opposite the Elliott trap (Jolly et al. 2019). Melomys were then given a further $10 \mathrm{~min}$ to explore the arena and interact with the novel object. Elliott traps remained open during the open field tests and melomys could shelter and emerge from them under their own volition. All trials were recorded using a GoPro HERO 3. A previous study in this system determined that melomys showed repeatable behaviour between trials (boldness: $R[ \pm 95 \% \mathrm{CI}]$ $=0.67[0.47,0.80], P<0.001$; emergence time: $R[ \pm 95 \% \mathrm{CI}]=0.73[0.53,0.83], P<0.001$; novel object: $R[ \pm 95 \% \mathrm{CI}]=0.61[0.209,0.974], P<0.001 ;$ Jolly et al. 2019$)$, therefore the data presented in this study were from a single behavioural trial of each animal $(n=146)$. Once trials were complete, each melomys was released at its point of capture.

To measure the boldness of individual melomys, we scored three behaviours typically associated with boldness and neophobia in rodents (Dielenberg \& McGregor 2001; McGregor et al. 2002; Réaleet al. 2007; Cremona et al. 2015): whether melomys fully emerged from their Elliott trap hide and entered the open arena during the $0-10$ min period (scored 0 or 1 , respectively); whether they fully emerged and entered the trial arena during the 10-20 min period (scored 0 or 1); and whether they interacted (touched) with the novel object that was placed in the arena during the 10-20 min period (scored 0 or 1). Videos were scored by a single observer who was blind to each melomys' origin and identity. Because interacting with the novel object was predicated on a melomys' willingness to emerge from their hide during the 10-20 min period, for analysis we combined their emergence during this period and interaction with the novel object into a single binary score: 0 (neophobic) $=$ did not emerge or emerged but did not interact with novel object; or 1 (not neophobic): emerged and interacted with novel object.

\section{Seed removal plots}

To assess whether the arrival of a novel predator affected the seed harvesting behaviour of granivorous melomys, we established seed removal plots at each site and sampled them each trapping session (night 6). After trapping and open field tests were conducted and melomys had been returned to their capture location, we set up 81 seed plots at each site by scraping away leaf litter with a shovel to create bare earth plots. These bare earth plots were created so that they were located in the centre between four Elliott traps within the 10x10 trapping grid. All seed plots were located randomly with respect to "distances to cover" but were all located on relatively open patches of ground. Sufficient within site replication $(n=81)$ significantly reduces the likelihood of distance to cover biasing population-level responses to seeds. Just before dark on the night of the seed removal experiment, we placed a single wheat seed in the centre of each bare earth plot. These seeds were either unscented, control seeds $(n=40)$ or predator-scented seeds that had been maintained in a sealed clip-lock bag filled with freshly collected northern quoll fur $(n=41)$. The placement of predator-scented and unscented seeds was alternated so that there was a chequered arrangement of scented and unscented seeds across the site. To ensure that the predator-scent was strong enough to be detected by melomys, along with the predator-scented seeds, we also placed a few strands of quoll fur around the predator-scented seeds. Before light the next morning, we returned back to each plot and counted the number of seeds of each scent-type that were removed from the plot. Melomys are the only nocturnal granivorous animal that occurs on Indian Island, and to avoid diurnal granivorous birds from removing seeds we conducted this experiment during the night only.

\section{Wildfire on northern Indian Island}

Immediately following our monitoring and experiments in August 2017, a wildlife broke out on northern Indian Island in the vicinity of the four quoll-invaded sites and burnt through all of the sites. Because of this, our experimental design is confounded by the fact that all of our quoll-invaded sites were burnt, and all of our quoll-free sites were unburnt. Fire is a regular disturbance in this landscape (Andersenet al. 2005), and previous work has shown little effect of fire on abundance, survival or recruitment of grassland melomys 
(Griffiths \& Brook 2015; Liedloff et al. 2018). Nonetheless, this confound exists and we proceed with caution when interpreting the effects of quolls on population size and survival of melomys.

\section{Statistical analysis}

During trapping sessions we identified individual melomys that were captured at each site by their unique microchips. Because melomys on Indian Island have very small home ranges (tending to be caught in the same or adjacent traps throughout the trapping period: Jolly et al. unpub. data) and since we never observed captures of melomys marked at other sites (Jolly et al. unpub. data), we treated each site as independent with regard to demographics and behaviour (Fig. 1; Table S1).

To estimate between-session survival, we analysed the mark-recapture data to estimate recapture and survival rates using Cormack-Jolly-Seber models in program MARK (see Supporting Information for details).

To test whether the presence of quolls impacted melomys population size, we used a hierarchical model in which population size was made a function of quoll presence/absence, capture session, and the interaction between these factors. Population size at each site during each session is estimated in this process, and we fitted this model in a Bayesian framework (see Supporting Information for details).

To assess whether the introduction of quolls affected the behaviour of melomys populations, we divided the responses of melomys in open field tests into two independent response variables: whether individuals emerged or not during the 0-10 min period (binomial: 0 or 1); and whether individuals emerged and interacted with the novel object or not during the 10-20 min period (binomial: 0 or 1). We used generalised linear mixedeffects models with binomial errors and a logit link to test the effect of quoll presence (two levels: quolls present and quolls absent) and trapping session (continuous), with site included as a random effect, on the behavioural response variables. $P$-values were obtained by likelihood ratio tests of the full model with the effect in question against the model without the effect. This analysis was performed using $\mathrm{R}$ with the $l m e 4$ software package (Bateset al. 2007).

To assess whether the numerical impact of quolls on melomys affected the seed harvesting rate of invaded melomys populations, we first examined the relationship between melomys population size (estimated above) and the total number of control (unscented) seeds harvested from each site. Here we used a simple linear model with number of seeds harvested as a linear function of population size, quoll presence/absence and the interaction between these effects. To test whether there was an additional effect of quoll presence, beyond their effect on population size, we defined a new variable, $\mathrm{ks}$, as the difference in seed take between scented and unscented treatments within each site.session. Here any effect of melomys density is cancelled out (because density is common to both treatments within each site.session). Thus, we fitted a model in which $\mathrm{ks}$ is a function of quoll presence/absence, session and the interaction between these effects. All analyses were performed using $\mathrm{R}$ version 3.3.2 ( $\mathrm{R}$ Core Team 2019).

\section{RESULTS}

\section{Effect of novel predator on survival}

When we assessed the impact of quolls on melomys survival between trapping sessions the best supported model was one in which survival rates between sessions were lower at quoll-invaded sites than at quollfree sites, and recapture rates were session-dependent (see Table S3). All other models were more than 4 AIC units from this best model, and so clearly inferior descriptions of the data. From the best-supported model, estimates of apparent survival $(S)$ for the intervals between the capture sessions were substantially higher at quoll-free sites $\left(S_{2017-2018}=0.368 ; S_{2018-2019}=0.225\right)$ than at quoll-invaded sites $\left(S_{2017-2018}=\right.$ $0.207 ; S_{2018-2019}=0.091 ;$ Fig. 2$)$. The differing survival probability between sessions is largely explained by the time difference between intervals (2017-2018 = 9 months vs. 2018-2019=13 months; Fig. 3).

\section{Hosted file}

image2.emf available at https://authorea.com/users/349935/articles/474906-trophic-cascadedriven-by-behavioural-fine-tuning-as-na\%C3\%AFve-prey-rapidly-adjust-to-a-novel-predator 
Figure 2. Between trapping session survival ( $\pm 95 \%$ CI) of grassland melomys (Melomys burtoni $)$ on Indian Island in quoll-invaded $(n=4)$ and quoll-free $(n=3)$ populations on Indian Island, Northern Territory, Australia.

Effect of novel predator on population size

Populations of melomys declined dramatically in quoll-invaded sites in the year following their introduction but not in quoll-free sites (Fig. 3). We observe a strong negative interaction between the presence of quolls and trapping session in 2018 (mean $=-1.194,95 \%$ credible interval [-1.732, -0.665]) and 2019 (mean $=-1.097$, 95\% confidence interval [-1.652, -0.551]; Fig. 3; see Table S2).

\section{Hosted file}

image3.emf available at https://authorea.com/users/349935/articles/474906-trophic-cascadedriven-by-behavioural-fine-tuning-as-na\%C3\%AFve-prey-rapidly-adjust-to-a-novel-predator

Figure 3. Posterior mean population sizes $\left(N_{k s} \pm 95 \% \mathrm{CI}\right)$ for quoll-invaded and quoll-free populations of grassland melomys (Melomys burtoni ) on Indian Island, Northern Territory, Australia. The orange dotted vertical line denotes the timing of the introduction of quolls. The red dotted vertical line denotes the timing of an unplanned fire that burnt through the quoll-invaded sites. In each predator treatment, different sites are denoted by different shaped points. Estimates assume closure of the population within each session and detection probability that varies across sessions.

Effects of novel predator on prey behaviour

For the proportion of melomys emerging in open field tests during the 0-10 min period, there was a significant interaction between quoll presence and trapping session $\left({ }^{2}(5)=4.386, P=0.04 ;\right.$ Fig. 4$)$. There was no interaction between quoll presence and trapping session for the proportion of melomys emerging and interacting with the novel object during $10-20 \mathrm{~min}$ period $\left({ }^{2}(5)=2.567, P=0.109 ;\right.$ Fig. 4$)$. The model without this interaction, however, revealed a significant effect of quoll presence, with fewer melomys emerging from hiding and interacting with the novel object during the 10-20 min period of open field tests from sites where quolls were present than from sites where quolls were absent $\left({ }^{2}(5)=-4.696, P<0.001\right.$; Fig. 4$)$.

\section{Hosted file}

image4.emf available at https://authorea.com/users/349935/articles/474906-trophic-cascadedriven-by-behavioural-fine-tuning-as-na\%C3\%AFve-prey-rapidly-adjust-to-a-novel-predator

Figure 4. Mean proportion ( $\pm 95 \% \mathrm{CI}$ ) of grassland melomys (Melomys burtoni ) emerging from hiding during open field tests from quoll-invaded sites in $2017(n=16), 2018(n=28)$ and $2019(n=29)$, and quoll-free sites in $2017(n=14), 2018(n=35)$ and $2019(n=24)$ on Indian Island, Northern Territory, Australia.

Effects of novel predator on seed harvesting and predator-scent aversion

Although there was no interaction between melomys density and quoll presence $\left(t_{18}=-0.251, P=0.805\right.$; Fig. 5a), there was a very clear positive relationship between melomys density and seed take $\left(t_{18}=5.112\right.$, $P<0.001$; Fig. 5a) and a clear negative relationship between quoll presence and seed take $\left(t t_{18}=-2.344, P\right.$ $=0.031$; Fig. 5a). When we looked at the difference in seed take $(\mathrm{ks})$ between scent treatments within site.session, a striking pattern emerges, in which there is a clear interaction between the presence of quolls and session $\left(F_{3,17}=18.61, P<0.001 ;\right.$ Fig. $\left.5 b\right)$.

\section{Hosted file}

image5.emf available at https://authorea.com/users/349935/articles/474906-trophic-cascadedriven-by-behavioural-fine-tuning-as-na\%C3\%AFve-prey-rapidly-adjust-to-a-novel-predator

Figure 5. (a) Effect of estimated population size on the number of control, unscented seeds removed from seed plots $(n=21)$ in quoll-invaded and quolls-free sites. Dotted lines denote the effect of quoll presence 
on seed removal rate. (b) Mean $( \pm 95 \%$ CI) difference () between the number of predator-scented seeds and control, unscented seeds removed by melomys from quoll-invaded $(n=3 ; 2017 \& n=4 ; 2018-19)$ and quoll-free $(n=4 ; 2017 \& n=3 ; 2018-19)$ sites during each trapping session.

\section{DISCUSSION}

The introduction of northern quolls to Indian Island was associated with lowered survival and an apparent drop in population size in quoll-invaded melomys populations. This numerical effect on melomys density had an impact on seed predation rates, because seed take is strongly associated with the density of melomys in this system. This is a classic trophic cascade: predation suppresses herbivore density, which reduces the pressure that herbivores place on primary producers. Our study, however, also reveals an additional, subtler, cascade effect; driven by altered prey behaviour rather than by altered prey density.

Within months of quolls appearing on the island, invaded populations of melomys were measurably shyer than nearby, predator-free populations of conspecifics. This rapid but generalised response to a novel threat appears to have had a subtle effect on seed predation rates: when we examine unscented seeds, per capita seed take is slightly lower in quoll-invaded populations. This generalised response appears to have been supplemented over time with more threat-specific antipredator behaviours. Although the boldness of predator-exposed melomys converged through time with that of predator-free melomys, predator-exposed melomys continued to be more neophobic than their predator-free conspecifics throughout the study. Meanwhile, predator-scent aversion, as evidenced by seed plots, steadily increased over time. Presumably the novel predation pressure imposed by quolls resulted in selection on behaviour and/or learning in impacted rodent populations, allowing them to fine-tune their behavioural response (decrease general shyness, but maintain neophobia, and respond to specific cues) as the nature of the threat became clearer. These changing behavioural responses imply a generalised reduction in seed take that becomes fine-tuned over time, with high risk sites (those that smell of predators) ultimately displaying substantially lower seed take than low risk sites. We see the emergence of a fine-scaled aversive response (varying on a spatial scale measured in the tens of metres) and affecting per capita rates of seed predation.

Although our study documented dramatic population declines in predator-invaded melomys populations, and we are assigning the primary cause of these declines to the introduction of quolls, we acknowledge there is potential for confounding factors to affect our results. We do not believe these confounds can explain our results, however (see Supporting Information). The primary confound is the unplanned fire that burnt through northern Indian Island after completion of our population monitoring in 2017. Such fires are commonplace in the Australian wet-dry tropics (Russell-Smith \& Yates 2007); a regular disturbance that is often rapidly offset by the annual monsoon driven wet season. Grassland melomys are adapted to fire in this system and populations have been shown to be very robust to its short- and long-term impacts (Griffiths \& Brook 2015; Liedloff et al. 2018). For these reasons (see Supporting Information for detailed rationale), we suspect the fire was unlikely to be directly responsible for the demographic effects we observed, and fire cannot in any way explain the behavioural response we observed to quoll-scented seeds. Our interpretation of these changes as being driven mostly by the addition of a novel predator to the system is the most parsimonious and globally coherent interpretation of the data.

Predation is a pervasive selective force in most natural systems, driving evolutionary change in prey morphology, physiology, life history and behaviour. Unlike morphology and physiology, however, the labile nature of behaviour makes it a particularly powerful trait for rapid response in a changing world (Réale et al. 2007; Sih et al. 2010b; Dall \& Griffith 2014). Behavioural comparisons of wild populations exposed to differing predation regimes provides some support for the prediction that reduced boldness would be selected for under high predation scenarios (Åbjörnsson et al. 2004; Bell 2005; Brydges et al. 2008) and that the appearance of novel predators can result in bold individuals becoming shyer (Niemelä et al.2012). The opposite pattern or a non-response can also occur, however (Brown et al. 2005; Urban 2007)(Laurila 2000; Carlson \& Langkilde 2014). Interestingly, a number of studies have demonstrated that individuals from high-predation areas were quicker to emerge (Harris et al. 2010) and were bolder and more aggressive (Bell \& Sih 2007; Dingemanse et al. 2007) than predator-naïve conspecifics. Although we found the opposite pattern to this immediately 
following the arrival of a novel predator, by the second year after predator introduction we found the boldness of melomys converging with that of predator-free populations. Thus, it is clear that the behavioural composition of these populations is dynamic, and it seems likely this dynamism (and perhaps the capacity of the prey species to identify specific threats) may explain some of the variation between earlier studies.

Although boldness may change over time, neophobia, as a generalised adaptive response to predation pressure, is now well supported across a number of studies (Crane et al. 2019). Individuals living under high predation risk scenarios have been shown to typically display generalized neophobia (Brown et al. 2015; Elvidge et al.2016), and neophobia can increase the survival of predator-naïve individuals in initial encounters with predators (Ferrari et al.2015; Crane et al. 2018). Certainly, in our study, predator-exposed melomys were significantly more neophobic than their predator-free conspecifics; an effect maintained throughout the study.

Despite reduced survival, significant population declines, and clear behavioural changes in invaded populations, it is impossible to determine from our data whether changes in the behaviour of predator-invaded melomys populations are the result phenotypic plasticity (learning) or natural selection. The low between trapping session survival of melomys in quoll-invaded populations means few individuals survive between sessions, so natural selection is a possibility, and selection on these behavioural traits is potentially very strong. Although behavioural changes in predator-invaded populations have been documented in a few systems where predator introductions have been staged and experimentally controlled (Lapiedraet al. 2018; Blumstein et al. 2019; Cunningham et al. 2019; Pringle et al. 2019), elucidating whether these observed changes arise because of behavioural plasticity or natural selection can be exceptionally difficult. Rapid behavioural responses of vulnerable prey to recovered predators has been observed in a single prey generation, presumably due to behavioural plasticity (Bergeret al. 2001; Cunningham et al. 2019). Similarly, behavioural adjustments to an introduced predator have been observed as a result of natural selection on advantageous behavioural traits (Lapiedra et al. 2018). In our study we had measures of individual behaviour, but our between session recapture rates of these individuals was too low to test whether individuals were altering their behaviour or whether natural selection was resulting in population-level change. It thus remains possible (and quite likely) that both mechanisms were in play.

Although northern quolls represent a novel predator to melomys on Indian Island, the two species' shared evolutionary history on the northern Australian mainland may provide some explanation as to why this staged introduction resulted in rapid, finely-tuned behavioural adjustment in melomys, rather than extinction. Isolation from predators can result in rapid loss of antipredator behaviours from a prey species' behavioural repertoire (Blumstein \& Daniel 2005; Jolly et al. 2018a), dramatically increasing an individual's susceptibility to predation following the introduction of either predator or prey (Carthey \& Banks 2014; Jolly et al. 2018b). But such outcomes are not inevitable: length of isolation, co-evolutionary history, degree of predator novelty, density-dependent effects, population size, and pre-existing predator-prey associations (Berger et al. 2001; Blumstein 2006; Banks \& Dickman 2007; Sih et al. 2010a; Carthey \& Banks 2014) are all likely hugely influential in determining whether an invaded population adjusts to the invader or proceeds towards extinction. Recently, a conservation introduction of Tasmanian devils to an island previously lacking them found that their possum prey rapidly adjusted their foraging behaviour to accommodate this newly arrived predator (Cunningham et al. 2019). Despite possums having lived on the island in isolation from devils since the 1950s, presumably, their long evolutionary history together on mainland Tasmania had them primed to respond to this predatory archetype (Sih et al. 2010a; Carthey \& Banks 2014; Cunningham et al. 2019). This shared evolutionary history is likely responsible for both possums' and melomys' ability to rapidly mount appropriate antipredator responses. The predators are novel within an individual's lifetime, but the individual's ancestors have encountered them before.

Although our results suggest that invaded melomys populations are beginning to adjust to the presence of northern quolls, there has been no sign of demographic recovery on the island. Data from our seed removal experiment clearly demonstrated that the function of melomys as seed harvesters and dispersers scales with density. Trophic cascades resulting from the addition and loss of predators from ecosystems has been 
observed in a number of systems globally (Ripple et al.2001; Terborgh et al. 2001; Estes et al. 2011), and the results can profoundly shape entire systems. As the only rodent and the dominant granivore in this system, while melomys populations may or may not go extinct as a result of quoll invasion, their reduced abundance and weakened ability to harvest and disperse seeds may have yet to be observed, longer-term consequences for the vegetation structure and ecosystem function of Indian Island (McConkey \& O'Farrill 2016). Currently, grass is a rare vegetation feature on Indian island (though it is a dominant feature of nearby savanna woodlands on the mainland), and this is quite possibly a result of the high density of melomys on this (previously) predator-free island. The presence of quolls may well change that, as both numerical and behaviour responses of melomys cascade down to the grass community.

Empirical research on the effects of novel predators on recipient communities under controlled conditions on a landscape-scale is exceptionally difficult and remains relatively rare. The introduction of threatened predators to landscapes from which they have been lost (Cunningham et al. 2019) or where they are entirely novel (Lapiedra et al. 2018), however, provides a unique opportunity to observe how naïve prey can respond to novel predators, and the mechanisms by which predators can structure communities. Our study provides empirical support that some impacted prey populations can adjust rapidly to the arrival of a novel predator via a generalised behavioural response (decreased boldness) followed by development of a species-specific antipredator response (behavioural fine-tuning). The arrival of the novel predator appears to have set off a trophic cascade that was driven, not only by changed prey density, but also by changed prey behaviour. Thus, rapid adaptive shift may allow prey populations to persist, but large-scale, system-wide changes may still follow.

\section{ACKNOWLEDGMENTS}

Thanks to Kenbi Traditional Owners (Raylene and Zoe Singh) for land access permission and Kenbi Rangers for assistance in the field. Special thanks to Kenbi Rangers (Brett Bigfoot, Rex Edmunds, Jack Gardner, Ian McFarlane, Dale Singh, and Rex Sing) for continued field assistance throughout this project. Thanks to Kenbi Ranger Co-ordinator Steven Brown for logistical support in the field. Thanks to Ella Kelly and Naomi Indigo for logistical and moral support on the island. Thanks to Alana de Laive for graphic design of figures. We thank two anonymous reviewers and Professor Réale for their comments via Peer Community in Ecology, which greatly improved the manuscript. This research was funded by an Australian Research Council Linkage Grant (JKW and BLP LP150100722). Animal ethics approval for this work was provided by the University of Melbourne (1814518) and Charles Darwin University (A13026) Animal Ethics Committees. In kind support was provided by Kenbi Rangers and the Northern Territory Government Department of Environment and Natural Resources, Flora and Fauna Division (via GRG). CJJ was supported by an Australian Postgraduate Award, the Holsworth Wildlife Research Endowment and David Hay Postgraduate Writing Up Award.

\section{REFERENCES}

Åbjörnsson, K., Hansson, L.-A. \& Brönmark, C. (2004). Responses of prey from habitats with different predator regimes: local, adaptation and heritability. Ecology , 85, 1859-1866.

Abrams, P.A. (2000). The evolution of predator-prey interactions: theory and evidence. Annu. Rev. Ecol. Syst. , 31, 79-105.

Andersen, A.N., Cook, G.D., Corbett, L.K., Douglas, M.M., Eager, R.W., Russell-Smith, J., et al. (2005). Fire frequency and biodiversity conservation in Australian tropical savannas: implications from the Kapalga fire experiment. Austral Ecol. , 30, 155-167.

Banks, P.B. \& Dickman, C.R. (2007). Alien predation and the effects of multiple levels of prey naiveté. Trends Ecol. Evol. , 22, 229-230.

Bates, D., Sarkar, D., Bates, M.D. \& Matrix, L. (2007). The lme4 package. $R$ package version , 2, 1-29.

Begg, R., Walsh, B., Woerle, F. \& King, S. (1983). Ecology ofMelomys burtoni, the grassland melomys (Rodentia: Muridae) at Cobourg Peninsula, N.T. Wildl. Res. , 10, 259-267. 
Bell, A.M. (2005). Behavioural differences between individuals and two populations of stickleback (Gasterosteus aculeatus ): behavioural syndromes. J. Evol. Biol. , 18, 464-473.

Bell, A.M. \& Sih, A. (2007). Exposure to predation generates personality in threespined sticklebacks (Gasterosteus aculeatus ).Ecol. Lett., 10, 828-834.

Berger, J., Swenson, J.E. \& Persson, I.-L. (2001). Recolonizing carnivores and naive prey: conservation lessons from pleistocene extinctions. Science, 291, 1036-1039.

Blumstein, D.T. (2006). The multipredator hypothesis and the evolutionary persistence of antipredator behavior. Ethology , 112, 209-217.

Blumstein, D.T. \& Daniel, J.C. (2005). The loss of anti-predator behaviour following isolation on islands. Proc. R. Soc. B , 272, 1663-1668.

Blumstein, D.T., Letnic, M. \& Moseby, K.E. (2019). In situpredator conditioning of naive prey prior to reintroduction. Phil. Trans. R. Soc. B , 374, 20180058.

Braithwaite, R. \& Griffiths, A. (1994). Demographic variation and range contraction in the northern quoll, Dasyurus hallucatus(Marsupialia: Dasyuridae). Wildl. Res. , 21, 203-217.

Brown, C. \& Braithwaite, V.A. (2004). Size matters: a test of boldness in eight populations of the poeciliid Brachyraphis episcopi .Anim. Behav. , 68, 1325-1329.

Brown, C., Jones, F. \& Braithwaite, V. (2005). In situexamination of boldness-shyness traits in the tropical poeciliid,Brachyraphis episcopi . Anim. Behav. , 70, 1003-1009.

Brown, G.E., Elvidge, C.K., Ramnarine, I., Ferrari, M.C.O. \& Chivers, D.P. (2015). Background risk and recent experience influences retention of neophobic responses to predators. Behav. Ecol. Sociobiol. , 69, $737-745$.

Brown, G.E., Ferrari, M.C.O., Elvidge, C.K., Ramnarine, I. \& Chivers, D.P. (2013). Phenotypically plastic neophobia: a response to variable predation risk. Proc. R. Soc. B , 280, 20122712.

Brydges, N.M., Colegrave, N., Heathcote, R.J.P. \& Braithwaite, V.A. (2008). Habitat stability and predation pressure affect temperament behaviours in populations of three-spined sticklebacks. J. Anim. Ecol. , 77, 229235.

Carlson, B.E. \& Langkilde, T. (2014). No evidence of selection by predators on tadpole boldness. Behaviour , 151, 23-45.

Carter, A.J., Feeney, W.E., Marshall, H.H., Cowlishaw, G. \& Heinsohn, R. (2013). Animal personality: what are behavioural ecologists measuring? Biol. Rev. , 88, 465-475.

Carthey, A.J.R. \& Banks, P.B. (2014). Naïveté in novel ecological interactions: lessons from theory and experimental evidence. Biol. Rev. , 89, 932-949.

Courchamp, F., Chapuis, J.-L. \& Pascal, M. (2003). Mammal invaders on islands: impact, control and control impact. Biol. Rev. , 78, 347-383.

Crane, A.L., Brown, G.E., Chivers, D.P. \& Ferrari, M.C.O. (2019). An ecological framework of neophobia: from cells to organisms to populations. Biol. Rev. , 218-231.

Crane, A.L., Chivers, D.P. \& Ferrari, M.C.O. (2018). Embryonic background risk promotes the survival of tadpoles facing surface predators. PLoS ONE , 13, e0193939.

Cremona, T., Mella, V.S.A., Webb, J.K. \& Crowther, M.S. (2015). Do individual differences in behavior influence wild rodents more than predation risk? J. Mammal. , 96, 1337-1343. 
Cunningham, C.X., Johnson, C.N., Hollings, T., Kreger, K. \& Jones, M.E. (2019). Trophic rewilding establishes a landscape of fear: Tasmanian devil introduction increases risk-sensitive foraging in a key prey species. Ecography , 42, 2053-2059.

Dall, S.R.X. \& Griffith, S.C. (2014). An empiricist guide to animal personality variation in ecology and evolution. Front. Ecol. Evol. , 2, 1-7.

Dielenberg, R.A. \& McGregor, I.S. (2001). Defensive behavior in rats towards predatory odors: a review. Neurosci. Biobehav. Rev. , 25, 597-609.

Dingemanse, N.J., Wright, J., Kazem, A.J.N., Thomas, D.K., Hickling, R. \& Dawnay, N. (2007). Behavioural syndromes differ predictably between 12 populations of three-spined stickleback. J. Anim. Ecol. , 76, 11281138 .

Doherty, T.S., Glen, A.S., Nimmo, D.G., Ritchie, E.G. \& Dickman, C.R. (2016). Invasive predators and global biodiversity loss. Proc. Natl. Acad. Sci. USA , 113, 11261-11265.

Elvidge, C.K., Chuard, P.J.C. \& Brown, G.E. (2016). Local predation risk shapes spatial and foraging neophobia patterns in Trinidadian guppies. Curr. Zool. , 62, 457-462.

Estes, J.A., Terborgh, J., Brashares, J.S., Power, M.E., Berger, J., Bond, W.J., et al. (2011). Trophic downgrading of planet Earth.Science, 333, 301-306.

Ferrari, M.C.O., McCormick, M.I., Meekan, M.G. \& Chivers, D.P. (2015). Background level of risk and the survival of predator-naive prey: can neophobia compensate for predator naivety in juvenile coral reef fishes?Proc. R. Soc. B , 282, 20142197.

Fortin, D., Beyer, H.L., Boyce, M.S., Smith, D.W., Duchesne, T. \& Mao, J.S. (2005). Wolves influence elk movements: behavior shapes a trophic cascade in Yellowstone National Park. Ecology , 86, 1320-1330.

Griffiths, A.D. \& Brook, B.W. (2015). Fire impacts recruitment more than survival of small-mammals in a tropical savanna. Ecosphere , 6, 1-22.

Harris, S., Ramnarine, I.W., Smith, H.G. \& Pettersson, L.B. (2010). Picking personalities apart: estimating the influence of predation, sex and body size on boldness in the guppy Poecilia reticulata .Oikos , 119, $1711-1718$.

Jolly, C.J., Kelly, E., Gillespie, G.R., Phillips, B. \& Webb, J.K. (2018b). Out of the frying pan: Reintroduction of toad-smart northern quolls to southern Kakadu National Park. Austral Ecol. , 43, 139-149.

Jolly, C.J., Webb, J.K., Gillespie, G.R., Hughes, N.K. \& Phillips, B.L. (2019). Bias averted: personality may not influence trappability.Behav. Ecol. Sociobiol. , 73, 129.

Jolly, C.J., Webb, J.K. \& Phillips, B.L. (2018a). The perils of paradise: an endangered species conserved on an island loses antipredator behaviours within 13 generations. Biol. Lett., 14, 20180222.

Kelly, E. (2019). Targeted gene flow for conservation: northern quolls and the invasive cane toad. PhD Thesis. University of Melbourne, Australia.

Kelly, E. \& Phillips, B.L. (2016). Targeted gene flow for conservation.Conserv. Biol. , 30, 259-267.

Kemper, C.M., Kitchener, D.J., Humphreys, W.F., How, R.A., Bradley, A.J. \& Schmitt, L.H. (1987). The demography and physiology of Melomyssp. (Rodentia: Muridae) in the Mitchell Plateau area, Kimberley, Western Australia. J. Zool. , 212, 533-562.

Lapiedra, O., Schoener, T.W., Leal, M., Losos, J.B. \& Kolbe, J.J. (2018). Predator-driven natural selection on risk-taking behavior in anole lizards. Science , 360, 1017-1020.

Laundre, J.W., Hernandez, L. \& Ripple, W.J. (2010). The landscape of fear: ecological implications of being afraid. TOECOLJ , 3, 1-7. 
Laurila, A. (2000). Behavioural responses to predator chemical cues and local variation in antipredator performance in Rana temporariatadpoles. Oikos , 88, 159-168.

Liedloff, A.C., Wilson, J.C. \& Engeman, R.M. (2018). The effect of wildfire on population dynamics for two native small mammal species in a coastal heathland in Queensland, Australia. Acta Oecol. , 88, 58-64.

Lima, S.L. \& Dill, L.M. (1990). Behavioral decisions made under the risk of predation: a review and prospectus. Can. J. Zool. , 68, 619-640.

Lopez, P., Hawlena, D., Polo, V., Amo, L. \& Martin, J. (2005). Sources of individual shy-bold variations in antipredator behaviour of male Iberian rock lizards. Anim. Behav. , 69, 1-9.

McConkey, K.R. \& O'Farrill, G. (2016). Loss of seed dispersal before the loss of seed dispersers. Biol. Conserv. , 201, 38-49.

McGregor, I.S., Schrama, L., Ambermoon, P. \& Dielenberg, R.A. (2002). Not all 'predator odours' are equal: cat odour but not 2,4,5 trimethylthiazoline (TMT; fox odour) elicits specific defensive behaviours in rats. Behav. Brain Res. , 129, 1-16.

Medina, F.M., Bonnaud, E., Vidal, E., Tershy, B.R., Zavaleta, E.S., Josh Donlan, C., et al. (2011). A global review of the impacts of invasive cats on island endangered vertebrates. Glob. Change Biol. , 17, 3503-3510.

Moore, H.A., Dunlop, J.A., Valentine, L.E., Woinarski, J.C.Z., Ritchie, E.G., Watson, D.M., et al. (2019). Topographic ruggedness and rainfall mediate geographic range contraction of a threatened marsupial predator. Divers. Distrib. , 25, 1818-1831.

Niemela, P.T., DiRienzo, N. \& Hedrick, A.V. (2012). Predator-induced changes in the boldness of naive field crickets, Gryllus integer, depends on behavioural type. Anim. Behav. , 84, 129-135.

Oakwood, M. (1997). The ecology of the northern quoll, Dasyurus hallucatus. PhD Thesis. Australian National University, Australia.

Oakwood, M., Woinarski, J.C.Z. \& Burnett, S. (2016). Dasyurus hallucatus (northern quoll). The IUCN Red List of Threatened Species 2016: e.T6295A21947321. http://dx.doi.org/10.2305/IUCN.UK.20162.RLTS.T6295A21947321.en. Downloaded on 31 October 2019.

Pringle, R.M., Kartzinel, T.R., Palmer, T.M., Thurman, T.J., Fox-Dobbs, K., Xu, C.C.Y., et al. (2019). Predator-induced collapse of niche structure and species coexistence. Nature , 570, 58-64.

R Core Team. (2019). R: A Language and Environment for Statistical Computing. R Foundation for Statistical Computing, Vienna.

Reale, D., Reader, S.M., Sol, D., McDougall, P.T. \& Dingemanse, N.J. (2007). Integrating animal temperament within ecology and evolution. Biol. Rev. , 82, 291-318.

Relyea, R.A. (2003). Predators come and predators go: the reversiblity of predator-induced traits. Ecology, $84,1840-1848$.

Ripple, W.J., Larsen, E.J., Renkin, R.A. \& Smith, D.W. (2001). Trophic cascades among wolves, elk and aspen on Yellowstone National Park's northern range. Biol. Conserv. , 102, 227-234.

Russell-Smith, J. \& Yates, C.P. (2007). Australian savanna fire regimes: context, scales, patchiness. Fire Ecol. , 3, 48-63.

Sax, D., Stachowicz, J., Brown, J., Bruno, J., Dawson, M., Gaines, S., et al. (2007). Ecological and evolutionary insights from species invasions. Trends Ecol. Evol. , 22, 465-471.

Schoener, T.W. \& Spiller, D.A. (1996). Devastation of prey diversity by experimentally introduced predators in the field. Nature, 381, 691-694. 
Shine, R. (2010). The ecological impact of invasive cane toads (Bufo marinus) in Australia. Q. Rev. Biol. , 85, 253-291.

Sih, A. (1992). Prey uncertainty and the balancing of antipredator and feeding needs. Am. Nat. , 139, 1052-1069.

Sih, A., Bolnick, D.I., Luttbeg, B., Orrock, J.L., Peacor, S.D., Pintor, L.M., et al. (2010a). Predator-prey naivete, antipredator behavior, and the ecology of predator invasions. Oikos , 119, 610-621.

Sih, A., Stamps, J., Yang, L.H., McElreath, R. \& Ramenofsky, M. (2010b). Behavior as a key component of integrative biology in a human-altered world. Integr. Comp. Biol. , 50, 934-944.

Sih, A., Ziemba, R. \& Harding, K.C. (2000). New insights on how temporal variation in predation risk shapes prey behavior. Trends Ecol. Evol. , 15, 3-4.

Simberloff, D., Martin, J.-L., Genovesi, P., Maris, V., Wardle, D.A., Aronson, J., et al. (2013). Impacts of biological invasions: what's what and the way forward. Trends Ecol. Evol. , 28, 58-66.

Suraci, J.P., Clinchy, M., Dill, L.M., Roberts, D. \& Zanette, L.Y. (2016). Fear of large carnivores causes a trophic cascade. Nature Comm. , 7, 10698.

Terborgh, J., Lopez, L., Nunez, P., Rao, M., Shahabuddin, G., Orihuela, G., et al. (2001). Ecological meltdown in predator-free forest fragments. Science, 294, 1923-1926.

Urban, M.C. (2007). Risky prey behavior evolves in risky habitats.Proc. Natl. Acad. Sci. USA , 104, 1437714382.

Woinarski, J.C.Z., Burbidge, A.A. \& Harrison, P.L. (2015). Ongoing unraveling of a continental fauna: decline and extinction of Australian mammals since European settlement. Proc. Natl. Acad. Sci. USA , 112, $4531-4540$.

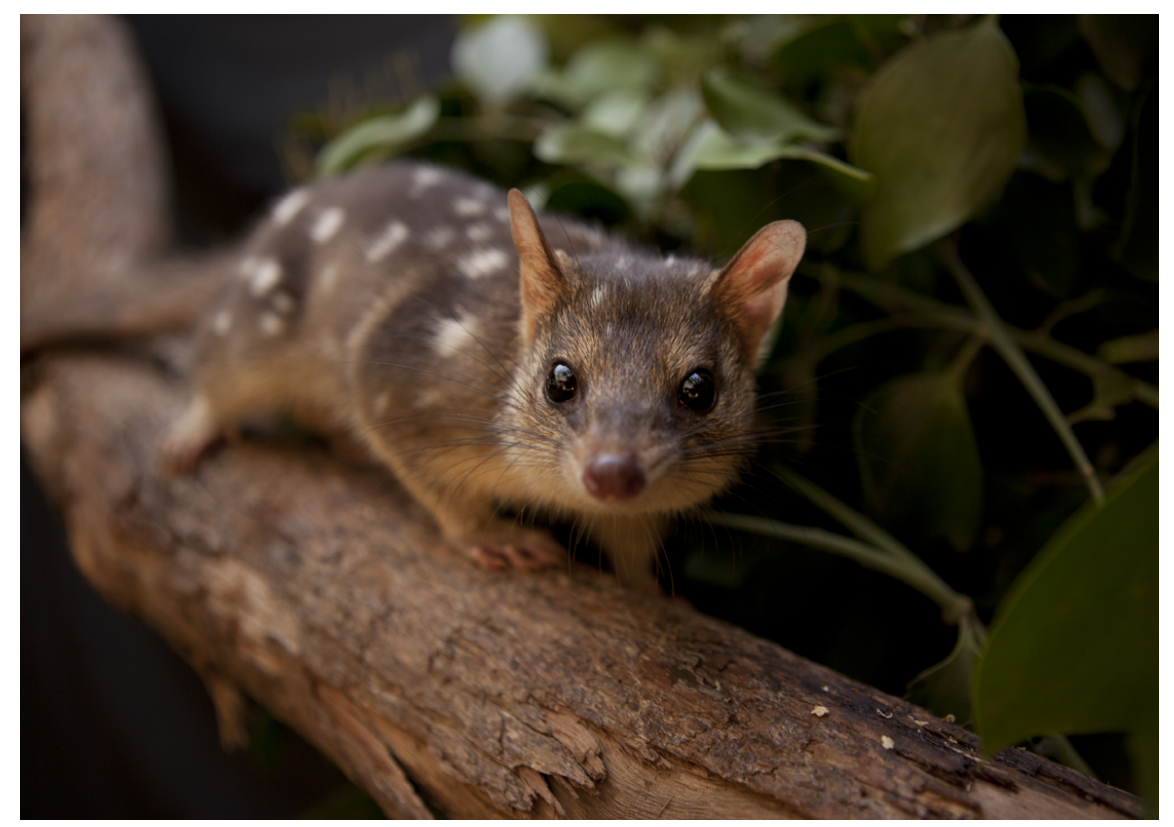

